\title{
Schmallenberg virus: experimental infection in goats and bucks
}

\author{
E. Laloy ${ }^{1 *}$ (D, M. Riou², C. Barc², G. Belbis ${ }^{3}$, E. Bréard ${ }^{4}$, S. Breton², N. Cordonnier ${ }^{1}$, D. Crochet ${ }^{2}$, R. Delaunay ${ }^{2}$, \\ J. Moreau ${ }^{2}$, N. Pozzi ${ }^{7}$, M. Raimbourg ${ }^{7}$, P. Sarradin² , S. Trapp ${ }^{5,6}$, C. Viarouge $^{4}$, S. Zientara ${ }^{4}$ and C. Ponsart ${ }^{7}$
}

\begin{abstract}
Background: Schmallenberg virus (SBV) is an emerging Orthobunyavirus of ruminant livestock species currently circulating in Europe. SBV causes a subclinical or mild disease in adult animals but vertical transmission to pregnant dams may lead to severe malformations in the offspring. Data on the onset of clinical signs, viremia and seroconversion in experimentally infected adult animals are available for cattle and sheep but are still lacking for goats.

For a better understanding of the pathogenesis of SBV infection in adult ruminants, we carried out experimental infections in adult goats. Our specific objectives were: (i) to record clinical signs, viremia and seroconversion; (ii) to monitor viral excretion in the semen of infected bucks; (iii) to determine in which tissues SBV replication took place and virus-induced lesions developed.

Results: Four goats and two bucks were inoculated with SBV. Virus inoculation was followed by a short viremic phase lasting 3 to 4 days and a seroconversion occurring between days 7 and 14 pi in all animals. The inoculated goats did not display any clinical signs, gross lesions or histological lesions. Viral genomic RNA was found in one ovary but could not be detected in other organs. SBV RNA was not found in the semen samples collected from two inoculated bucks.
\end{abstract}

Conclusions: In the four goats and two bucks, the kinetics of viremia and seroconversion appeared similar to those previously described for sheep and cattle. Our limited set of data provides no evidence of viral excretion in buck semen.

\section{Background}

In the late summer/autumn 2011, a disease outbreak with diarrhea, drop of milk production, and fever was reported in adult cattle in Western Europe. These symptoms could not be attributed to any known infectious agent. Metagenomic analyses on blood samples from affected animals in Germany led to the identification of a new Orthobunyavirus that was named the Schmallenberg virus (SBV) [1]. This emerging virus was later found to induce teratogenesis in pregnant cattle, sheep, and goats leading to typical malformations in the offspring [2].

Experimental infections of adult sheep and cattle with SBV resulted in subclinical infections with a short viremic

\footnotetext{
* Correspondence: elaloy@vet-alfort.fr

'Université Paris-Est, Ecole Nationale Vétérinaire d'Alfort, Unité d'anatomie pathologique, 7 avenue du Général de Gaulle, 94704 Maisons-Alfort, France Full list of author information is available at the end of the article
}

phase. Seroconversion in the infected animals occurred about two weeks post inoculation (pi) [1,3-5]. To our knowledge, no report on the pathogenesis of experimental SBV infections in adult goats has been published.

SBV is transmitted by biting midges (Culicoides spp.). The possibility of sexual transmission between ruminants has not yet been elucidated [2]. Infectious SBV has been detected in bovine semen samples from the field [6-8] and SBV RNA could be detected in semen from experimentally infected bulls [9]. Whether SBV can be excreted in buck semen is still unknown.

In this study, we carried out experimental infections of SBV in adult goats. Our specific objectives were: (i) to record the development of clinical signs, viremia and seroconversion in goats; (ii) to monitor the excretion of SBV in buck semen after inoculation; (iii) to determine in which tissues SBV replication took place and virus- 
induced lesions developed in adult bucks and non-gravid goats, with special emphasis on the genital tract.

\section{Methods}

All experiments were conducted in accordance with the guidelines of the Council European Directive (2010/63/ UE). All experimental procedures were approved by the ethical review board of the Val de Loire (CEEA VdL, committee number $\mathrm{n}^{\circ} 19$, number 2012-02-11).

\section{Experimental design}

Five adult Alpine goats, one adult Saanen buck and one adult Alpine buck were purchased from local breeders (INRA Center, Bourges, France) and were housed in the Biosafety Level 3 and insect-proof animal facilities of the National Institute of Agricultural Research (INRA), Research Loire Valley Center (PFIE, Nouzilly, France). All purchased animals were SBV-negative as determined by ELISA and RT-qPCR.

Two goats (designated A and B) were inoculated subcutaneously on day 0 with $1 \mathrm{~mL}$ of SBV-containing bovine serum kindly provided by the Friedrich-Loeffler-Institut (FLI), Germany [3]. Two goats (designated C and D) were inoculated on day 0 with $1 \mathrm{~mL}$ of SBV-containing ovine whole blood collected at the PFIE during a previous experimental infection trial [5]. One goat from each group was killed at day 7 pi and the remaining goats were killed at day 14 pi. The two bucks (designated $\mathrm{E}$ and $\mathrm{F}$ ) were inoculated subcutaneously at day 0 with $1 \mathrm{~mL}$ of the FLI serum and killed at day 28 pi. One goat (designated G) was inoculated subcutaneously on day 0 with $1 \mathrm{~mL}$ of sterile saline solution and served as an in-contact negative control until it was killed at day 28 pi.

During the course of the trial, all animals were monitored twice daily, and body temperatures were recorded by telemetric measurement with rumen temperature sensors (Small Bolus ${ }^{\circ}$, Médria, Châteaubourg-France). After inoculation, whole blood and serum samples were collected daily during the first week and then at days 14 and 28 pi. Buck semen was collected at day 0 and then twice a week. At necropsy, all the organs were macroscopically evaluated and a panel of tissue samples was collected for histopathology and RT-qPCR (spleen, prescapular lymph node, skeletal muscle, aorta, liver, kidney, lung, small intestine, brain, skin, ovary, oviduct, uterus, testis, and epididymis).

\section{Real-time PCR}

Ovaries were dissected and follicular fluid, cumulus cells, oocytes and interstitial tissue were separated from each other prior to total RNA extraction. RNA from blood and tissue samples was extracted using the LSI MagVet ${ }^{\mathrm{mi}}$ Universal Isolation kit (Life Technologies SAS, SaintAubin, France) and King Fisher magnetic particle processor (Thermo Scientific ${ }^{\text {Th }}$, Illkirch, France) according to the manufacturers' instructions. RNA from semen samples was extracted with Trizol ${ }^{\circ}$ LS Reagent [6].

The samples were then tested for the presence of SBV RNA by RT-qPCR as previously described [10]. Quantification cycle $(\mathrm{Cq})$ threshold value was 40 , with higher values regarded as negative.

\section{Serology}

Serum samples were submitted to SBV specific ELISA testing (ID Screen Schmallenberg virus Indirect ${ }^{\circ}$, monocupule, IDvet) and virus neutralization test (VNT) [11].

\section{Histopathological examination}

After fixation in $10 \%$ buffered formalin, tissues were routinely processed, sliced at $4 \mu \mathrm{m}$, stained with Hematoxylin-Eosin-Saffron (HES) and examined by light microscopy.

\section{Results}

\section{Clinical and post-mortem observations}

The goats and bucks did not exhibit any clinical signs. No fever peak was detected in any of the animals. No significant gross lesion was found at necropsy.

\section{Real-time PCR}

SBV RNA was detected in the blood of all inoculated animals for 3 to 4 days, starting between day 1 and 3 pi (Fig. 1). From day 6 pi, SBV RNA became undetectable. $\mathrm{Cq}$ values during RNAemia in all animals ranged from 25 to 39 . The intensity of RNAemia differed in 2 of the 4 inoculated goats, with goats $\mathrm{A}$ and $\mathrm{D}$ showing a maximal Cq value of about 25 while goats $B$ and $C$ showed a maximal $\mathrm{Cq}$ value of about 35, independently of the inoculum (ovine EDTA blood or bovine serum). All sampled tissues scored negative for SBV by RT-qPCR in

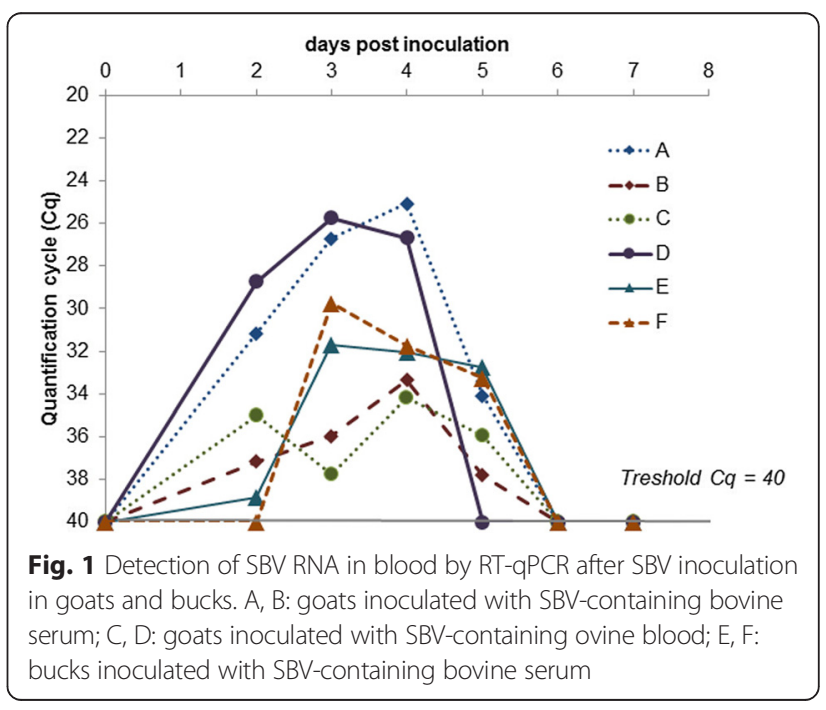


bucks and goats, except for one ovary in goat $\mathrm{C}$ (interstitial ovarian tissue with a non-normalized $\mathrm{Cq}$ value of 34). The semen from the bucks remained negative for SBV from day 0 until the end of the trial, as determined by RT-qPCR.

\section{Serology}

The ELISA results for inoculated animals are shown in Fig. 2. Goats B and C, killed at day 7 pi, remained seronegative. Antibodies to SBV were detected in goats A and $\mathrm{D}$ at 14 pi by ELISA and at day 9 pi by VNT (titers: 128 and 96 respectively). Antibodies to SBV were detected in buck E at day 28 pi by ELISA and at day $14 \mathrm{pi}$ by VNT (titer: 64). Buck F was found seropositive at day 14 pi by ELISA and VNT (titer: 96). The mockinoculated goat remained seronegative until day $28 \mathrm{pi}$ (as determined by ELISA).

\section{Histopathological examination}

No significant lesions was found in any of the animals. Rare coccidian parasites were seen in the intestine from goats $\mathrm{B}, \mathrm{C}$ and $\mathrm{G}$.

\section{Discussion}

Our results show that, in goats and bucks, inoculation of SBV is followed by a short viremic phase lasting 3 to 4 days followed by seroconversion between day 7 and day 14 pi. Importantly, these clear signs of successful experimental infection were not accompanied by any clinical sign, including fever.

These observations are in accordance with data from experimental infection studies with sheep and cattle inoculated subcutaneously with infectious serum. In sheep, RNAemia was detected a few days after infection and lasted

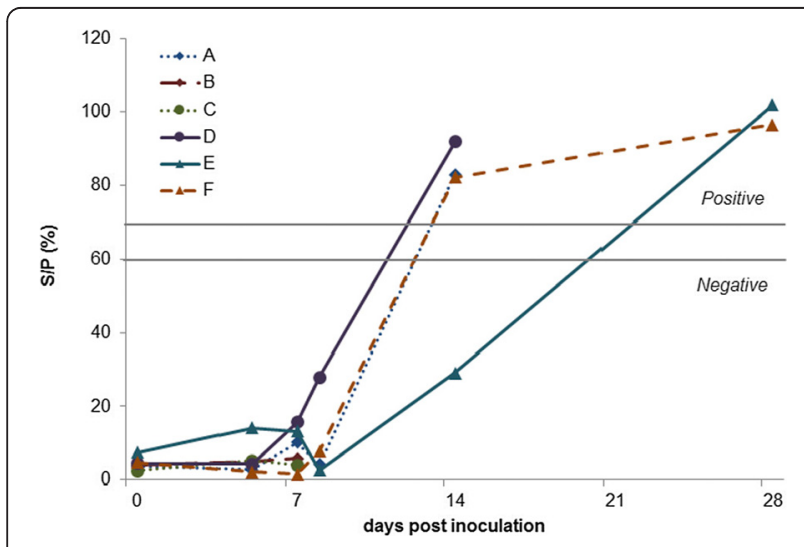

Fig. 2 Detection of SBV specific antibodies by ELISA after SBV inoculation in goats and bucks. A, B: goats inoculated with SBV-containing bovine serum; C, D: goats inoculated with SBVcontaining ovine blood; E, F: bucks inoculated with SBVcontaining bovine serum. S/P $<60 \%$ : negative; S/P $>70 \%$ : positive and S/P between $60 \%$ and $70 \%$ : doubtful for 3 to 7 days, while SBV-specific antibodies appeared between 7 and 9 days pi (detection by VNT) [12] or between 10 and 14 days pi (detection by ELISA) [5]. Data from this experiment in goats show a trend towards a higher sensitivity of VNT compared to ELISA at the beginning of the seroconversion. Poskin et al. [12] had similar observations in sheep and suggested that this difference could be due to the ability of VNT to detect both IgM and IgG, while the ELISA can only detect IgG. Following experimental infection, sheep did not show any clinical sign [12] or almost no sign, with diarrhea being reported in one case [5]. In cattle, RNAemia could be detected for less than a week after inoculation $[1,3,4]$ with detection by ELISA of SBV-specific antibodies two weeks pi [3, 4]. Clinical signs were absent $[3,4]$ or limited to fever or diarrhea [1].

In cattle and sheep, after experimental inoculation, SBV genomic RNA was most consistently found in lymphoid organs, i.e. spleen and lymph nodes, especially the mesenteric lymph nodes $[3-5,9,12]$. This was not the case in any of the four goats and two bucks inoculated in the present study; however we did not collect the mesenteric lymph nodes. The only organ where SBV genome was found was one ovary of a single goat. Interestingly, the SBV genome had already been found in the ovary of one experimentally infected sheep [5], but the significance of this finding remains unknown. No significant gross lesions or histological lesions were found in our study. Similarly, experimental infections of cattle or sheep did not result in gross lesions at necropsy [3-5, 12]. So far, in experimentally infected adult ruminants, the presence of SBV genome in a given organ has not been reported to be associated with any lesion in this organ.

No SBV genome was found between day 0 and day 28 pi (end of the trial) in the semen samples obtained from the two inoculated bucks. This result differs from the observations made after experimental infection of two bulls with SBV-containing cell culture supernatants [9]. Viral genome could be detected in the semen of both bulls for the first week following inoculation and, in the case of one bull, as late as at day 19 pi (the trial ended at day 25 pi). SBV excretion in bovine semen has also been reported from the field [6-8] but, to our knowledge, this has never been reported for bucks. However, the small size of our inoculated group precludes a conclusion regarding the excretion of SBV in caprine semen and the risk of sexual transmission.

The data from this study match those from reports of natural infection by SBV in domestic ruminants: clinical signs of infection are either mild or absent in adults. The most important effects of SBV infection are malformations in the offspring due to vertical transmission in pregnant dams [2]. A study of the impact of SBV in French domestic ruminants showed that only $2 \%$ of the kids born in goat herds with congenital SBV cases showed 
malformations [13]. The same study reported a potential effect of SBV infection in the early stages of pregnancy, based on reports of repeated estrus or early embryonic loss, especially in small ruminants [13]. The effects of SBV infection in pregnant goats, however, remain to be elucidated.

\section{Conclusions}

Following experimental infection in goats with SBV, the kinetics of viremia and seroconversion were found to be similar to earlier reported kinetics in sheep and cattle. No clinical signs were associated to infection, in agreement with reports from the field. SBV RNA was found in one ovary but not in other organs. The SBV genome was not found in semen from the two inoculated bucks but this limited set of data does not exclude the risk of viral transmission by artificial insemination or natural service.

\section{Abbreviations}

Cq: Quantification cycle; FLI: Friedrich-Loeffler-Institut; HES: Hematoxylineosin-saffron; PFIE: Plate-Forme d'Infectiologie Expérimentale; pi: Post inoculation; SBV: Schmallenberg virus; VNT: Virus neutralization test.

\section{Competing interests}

The authors declare that they have no competing interests.

\section{Authors' contributions}

Study conception and design: ST, SZ, CP, PS, MRi, EB. Acquisition of data: EL, $\mathrm{CB}, \mathrm{GB}, \mathrm{EB}, \mathrm{SB}, \mathrm{NC}, \mathrm{DC}, \mathrm{JM}, \mathrm{NP}, \mathrm{MRa}, \mathrm{MRi}, \mathrm{CV}, \mathrm{RD}$. Analysis and interpretation of data: EL, EB, NP, CP, SZ, MRi. Drafting of manuscript: EL. Critical revision: $E B, S Z, N C, S T, C B, C P, M R i$. All authors read and approved the final manuscript.

\begin{abstract}
Acknowledgements
This study was supported and financed by the European Union (Council decision 2012/349/EU) and the General Direction of Food (DGAL, Ministry of Agriculture) for studies on Schmallenberg virus. We are grateful to Thierry Pineau, the leader of department of Animal Heath in INRA, coordinator of European project for the experiments with goats in France. We wish to thank Kerstin Wernike (FLI) for providing infectious bovine serum. Many thanks to the direction of the PFIE, especially Bertrand Schwartz, and to the zootechnical staff of the PFIE, especially the team working in confinement unit with the goats. We thank Marc Chodkiewicz for careful editing of the manuscript.
\end{abstract}

\begin{abstract}
Author details
${ }^{1}$ Université Paris-Est, Ecole Nationale Vétérinaire d'Alfort, Unité d'anatomie pathologique, 7 avenue du Général de Gaulle, 94704 Maisons-Alfort, France. ${ }^{2}$ INRA Centre Val de Loire, UE-1277 Plateforme d'Infectiologie Expérimentale, secteur 3, route de Crotelles, 37380 Nouzilly, France. ${ }^{3}$ Université Paris-Est, Ecole Nationale Vétérinaire d'Alfort, Unité de pathologie des animaux de production, 7 avenue du Général de Gaulle, 94704 Maisons-Alfort, France. ${ }^{4}$ ANSES, UMR 1161 Virologie ANSES-INRA-ENVA, 23 avenue du Général de Gaulle, 94704 Maisons-Alfort, France. ${ }^{5}$ INRA Centre Val de Loire, UMR 1282 Infectiologie et Santé Publique, 37380 Nouzilly, France. ${ }^{6}$ Université François Rabelais de Tours, UMR 1282 Infectiologie et Santé Publique, 37000 Tours, France. ' ${ }^{7}$ NCR, Laboratoire national de contrôle des reproducteurs, 13 rue Jouët, 94703 Maisons-Alfort, France.
\end{abstract}

Received: 2 May 2015 Accepted: 30 July 2015

Published online: 22 August 2015

\section{References}

1. Hoffmann B, Scheuch M, Höper D, Jungblut R, Holsteg M, Schirrmeier H, et al. Novel Orthobunyavirus in Cattle, Europe, 2011. Emerg Infect Dis. 2012;8:469-72

2. Wernike K, Conraths F, Zanella G, Granzow H, Gache K, Schirrmeier H, et al. Schmallenberg virus-two years of experiences. Prev Vet Med. 2014;116:423-34.

3. Wernike K, Eschbaumer M, Breithaupt A, Hoffmann B, Beer M. Schmallenberg virus challenge models in cattle: infectious serum or culture-grown virus? Vet Res. 2012;43:84.

4. Wernike K, Eschbaumer M, Schirrmeier H, Blohm U, Breithaupt A, Hoffmann B, et al. Oral exposure, reinfection and cellular immunity to Schmallenberg virus in cattle. Vet Microbiol. 2013;165:155-9.

5. Wernike K, Hoffmann B, Bréard E, Bøtner A, Ponsart C, Zientara S, et al. Schmallenberg virus experimental infection of sheep. Vet Microbiol. 2013;166:461-6.

6. Hoffmann B, Schulz C, Beer M. First detection of Schmallenberg virus RNA in bovine semen, Germany, 2012. Vet Microbiol. 2013;167(3-4):289-95.

7. Ponsart C, Pozzi N, Bréard E, Catinot V, Viard G, Sailleau C, et al. Evidence of excretion of Schmallenberg virus in bull semen. Vet Res. 2014;45:37.

8. Schulz C, Wernike K, Beer M, Hoffmann B. Infectious Schmallenberg virus from bovine semen, Germany. Emerg Infect Dis. 2014;20:338-40.

9. Van Der Poel WH, Parlevliet JM, Verstraten ER, Kooi EA, Hakze-Van Der Honing R, Stockhofe N. Schmallenberg virus detection in bovine semen after experimental infection of bulls. Epidemiol Infect. 2014;142:1495-500.

10. Bilk S, Schulze C, Fischer M, Beer M, Hlinak A, Hoffmann B. Organ distribution of Schmallenberg virus RNA in malformed newborns. Vet Microbiol. 2012;159:236-8.

11. Bréard E, Lara E, Comtet L, Viarouge C, Doceul V, Desprat A, et al. Validation of a commercially available indirect ELISA using a nucleocapside recombinant protein for detection of Schmallenberg virus antibodies. PLoS One. 2013;doi: 10.1371/journal.pone.0053446.

12. Poskin A, Martinelle L, Mostin L, Van Campe W, Dal Pozzo F, Saegerman C, et al. Dose-dependent effect of experimental Schmallenberg virus infection in sheep. Vet J. 2014;201:419-22.

13. Dominguez M, Gache K, Touratier A, Perrin JB, Fediaevsky A, Collin E, et al. Spread and impact of the Schmallenberg virus epidemic in France in 2012-2013. BMC Vet Res. 2014;10:248.

\section{Submit your next manuscript to BioMed Central and take full advantage of:}

- Convenient online submission

- Thorough peer review

- No space constraints or color figure charges

- Immediate publication on acceptance

- Inclusion in PubMed, CAS, Scopus and Google Scholar

- Research which is freely available for redistribution 